\title{
The Interpretation of Freedom in the Letters of Paul
}

\author{
With Special Reference to the 'German' Tradition
}

[Die Interpretation von Freiheit in den Briefen des Paulus. Unter besonderer Bezugnahme auf die 'deutsche' Tradition.]

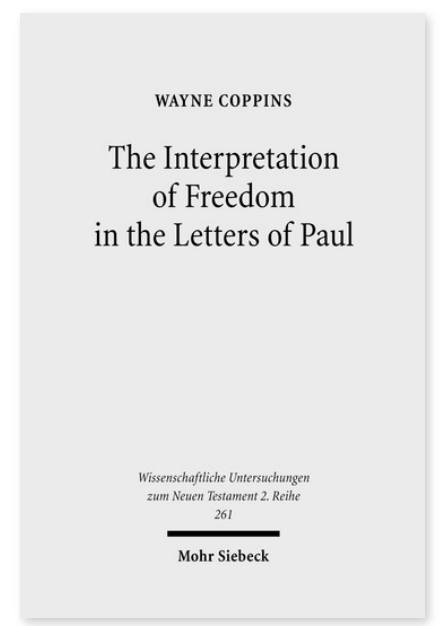

2009. XIV, 218 Seiten. WUNT II 261

ISBN 978-3-16-151604-7

DOI 10.1628/978-3-16-151604-7

eBook PDF

ISBN 978-3-16-149969-2

fadengeheftete Broschur 74,00€
Veröffentlicht auf Englisch.

Wayne Coppins untersucht die Interpretation von Freiheit in Paulus' Briefen insbesondere im Hinblick auf Martin Luther und die deutsche neutestamentliche Wissenschaft des 20. Jahrhunderts. Er konzentriert sich auf drei Hauptthemen: die Bedeutung der Freiheit in Paulus' Briefen und Theologie, die Schlüsselstellung und Bedeutung der 'Freiheit vom Gesetz' und die Beziehung zwischen Freiheit und Liebe. Zusätzlich zu einer detaillierten Exegese der paulinischen Schlüsseltexte bietet der Autor eine Synthese der besagten Themen und beschließt die Studie mit einer rückblickenden Bewertung des Versprechens und der Fallstricke der 'deutschen' Wissenschaft über die Freiheit bei Paulus.

Wayne Coppins is Professor of Religion at the University of Georgia.

Jetzt bestellen:

https://mohrsiebeck.com/buch/the-interpretation-of-freedom-in-the-letters-of-paul-9783161516047?no_cache=1 order@mohrsiebeck.com

Telefon: +49 (0)7071-923-17

Telefax: $+49(0) 7071-51104$ 